\title{
A Note on the Action of Morphine upon the Intestinal Movements in Rabbits.
}

\author{
By \\ Kimio Abe. \\ (安部公男) \\ (From the Physiological Laboratory of Prof. Y. Satake, \\ Tohoku Imperial University, Sendai.)
}

The findings of $\mathrm{H}$ ay a $\mathrm{ma}^{1)}$ that interference of the suprarenals or the splanchnic nerves considerably reduces or abolisbes the inhibiting influence of morphine, intravenously applied, upon the intestinal movements in rabbits, seem to afford an evidence supporting an accelerating action of the drug upon the epinephrine secretion from the suprarenals.

In reading the paper we noticed however first of all the fact that a rather fundamental difference was yielded in his hands before and after cutting the splanchnic nerves, notwithstanding that the intestines were not particularly deprived of the innervation besides that the splanchnic nerves were out, as above related, in the later half of the experiment. It must be noted here in passing that we have no doubt of an accelerating action of morphine upon the epinephrine discharge rate from the suprarenals. ${ }^{2)}$ It is therefore certainly worth while to ask whether his findings will be duplicated by any other experimentalists.

We find some references rê the fact that the denervation of intestines am. plifies the reaction of intestines against morphine (Pal, Rodari, Benczur,

1) H a ya ma, Folia pharm. Jap., 1928, 7, 128 (Jap., German abstract: Breviaria

2) Sato and $0 \mathrm{hmi}$, Tohoku J. of Exp. Med., 1933, 21, 411. A rather complete review there; a paper from the Boston Physiological Laboratory was regrettably overlooked there: Harmon and MeFall J. Pharm. \& Exp. Ther., 1929, 27, 147 (denervated heart; acceleration). 
and Plant and Miller). ${ }^{3}$; Nothnagel and Spitzer reported the data, which might be interpretable similarly. ${ }^{3 \text { ) }}$ Dreyer noted a different outcome. ${ }^{3}$ )

3) N a sse, Ctrlbl. f. med. Wiss., 1865, 3. year, 785 (Rabbits, opium, accelerates intestinal movements and increases excitability of intestines.). Gscheidle n, Unters. a. physiol. Labor. in Würzburg, II part, 1869 Leipzig, 66 (Rabbits, morphine, increases excitability of intestines.). Le gros and $0 \mathrm{nim}$ us, J. l'Anat. et Physiol., 1869, 6. year, 187 (A dog, ballon in intestine fistula, 1 meter from caecum, morphine, retards intestinal movements, but never arrests; irritation on electric stimuli not changed.). Salvioli, Arch. f. Anat. u. Physiol., Physiol. Abt. 1880, Supp., 109 f. (Dogs, opium, application through blood vessels, relaxes intestines; not relaxes ring muscles, but contracts.). Noth n a gel Virchows Arch., 1882, 89, 1 (Rabbits under ether, saline bath, morphine, subcutaneously, 0.029 inhibits intestinal movements by exciting inhibitory nerves, large a mounts increase the movements by paralysing the nerves.). B ok a i, Arch. f, exp. Path.u.Pharm., 1887, 23, 418(Rabbits, morphine, 0.01-0.03 grm. inhibits intestinal movements, $0.04 \mathrm{grm}$. augments.). P a land $\mathrm{B}$ erggr ü $\mathrm{n}$, Cit. in S tarken ste in in Heff ter: Handbuch d.experimentellen Pharmakologie, II Vol. II Part, 1924, 89 (Rabbits, morphine, small amounts diminishes excitability of intestines.). S pitzer, Virchows Areh., 1891, 123, $612 \mathrm{ff}$. (Rabbits, saline bath, morphine acts to inhibit intestine movement through central mechanism and slightly reduces excitation of intestines.). J a co bj, Arch. f. exp. Path. u. Pharm., 1892, 29, $208 \mathrm{ff}$. (Starving rabbits, morphine, increases excitation of intestines.). Po bl, Ibid., 1894, 34, $98 \mathrm{ff}$. (Rabbits, morphine, stimulates in loco intestine muscles, then paralyses. Exceptionally only relaxes, reduces excitability.). Schmiede berg, Grundriss der Pharmakologie, II ed., 1895 Leipzig, p. 74 (Morphine paralyses the sensory nervous endings in intestines.). Vámoss y, D.m.W., 1897, 457 (Rabbits, saline bath; morphine, reduces vagal action; no strong perisatalsis on large amonnts, contrary to Nothnagel; on applying into intestinal canal reduces local excitability, but never abolishes.). Bu noh, J. of Physiol,, 18 (97-) 98, 22, 357 (Rabbits, dogs, cats, morphine, small amounts no action. $15-20 \mathrm{mgrms}$. were tried to dogs \& cats.). Bayliss and S tarling, Ibid., 1899. 24. $177 \mathrm{ff}$. (Dogs, exposed intestines, morphine almost no effects.). Hirsch, Ctrlbl. f. inn. Med., 1901, 22 year, 33 (Dogs, morphine, delays emptying of stomach.). Pal, Wiener med. Presse, 1900, 41 year, 2042; Ctrlbl. f. Physiol., 1902 $(-3), 16,68$ (Dogs under curara or chloroform, vagotomy, morphine augments rhythmic movements \& tone of intestines.). Dixon, J. of Physiol., 1904, 30, 106 (Opium, morphine, apocodeine, cats: augments tone and peristalsis of intestines; dogs: a short period inhibition followed soou by increasing movements.). Magnus, Ergeb. d. Physiol., 1903, II 2, $637 \mathrm{ff}$. (Summary \& critics: Morphine rests intestines in men and rabbits \& augments in dogs, both by acting on intestines themselves.). Magnu s, Pflugers Arch., 1906, 115, 315 (Rabbits under ether, he cannot verify the statements of Noth. nage 1. Morphine arrests in cats diarrhoea due to milk; small doses cause vomiting \& diarrhoea.). M ag nus, Ibid., 1908, 122, 210 (Isolated intestines of cats, rabbits : slight excitement on too large doses only. X-ray examination: morphine does not alter intestinal passage; the author laid much stress on the passage throngh pylorus. This view of $\mathrm{M}$. was attacked by $\mathrm{S} \mathrm{chmiede}$ berg, Grundriss der Pharmakologie, 7. ed., 1913 Leipzig, 138.). Rodari, Ther. Monatsh., 1909, 23. year, 543 (Rabbits, pantopon, increases intestinal movements temporarily.). Padtberg, Pflügers Arch., 1909, 129, 476 ( $M$ ag nu s' laboratory, cats, morphine arrests $\mathrm{Hg} \mathrm{SO}_{4}$-diarrhoea by acting on pylorus.). A rnsperger, Verh. d. Kongr. f. inn. Med., 1910, 27, 333 (Men, X-ray examination, morphine retards intestinal movements. He referred that his finding coincides with that of Gottlieb on dog provided with Thiry-Vella's fistula.). Vonden Velden, Verhandl. d. Kongr. f. inn. Med., 1910, 27, 339 (Healthy persons, morphine, excites peristalisis in stomach.). Bencz úr, Intern. Beitr. z. Path. u. Ther. d. Verdgsstör., 1910, 1, 5 (Dogs, Thiry-Vella's fistula, morphine, accelerates peristalsis and contracts intes- 
We realize that our work so far is very incomplete in that it was in fact carried out some years ago without acknowledging an impor-

tines, never paralyses.). Pa d tb e rg, Pfligers Arch., 1911, 139, 318 (Cats, morphine retards intestinal movements caused by colocynthin.) Cohnheim and Modrakowski, Hoppe-Seyler's Ztsehr., 1911, 71, 273 (Dogs, morphine, not alters speed of intestinal passage.). S ch wenter, Fortschr. auf d. Geb. d. Röntgenstr., $1912(-13), 19,1$ (Cats, Xray, relaxes peristalsis of intestines.). Stierlin and $\mathrm{Sch}$ apiro, M.m.W., 1912, 2714 (Men with fistula, in the half of cases, morphine retards passage through intestines, particularly lower portion; dogs with fistula, morphine, contracts intestines on mediate \& large doses.). Popper, D.m.W., 1912, 308, Popper and Frankl, Ibid., 1318 (Intestines of rabbits, cats, dogs: morphine augments pendulum movements \& tone of circular \& longitudinal muscles; pantopon reduces tone of longitudinal muscle.). $\mathrm{Zeh}$ be, M, m.W., 1912, 1543 (Men, X-ray-examination: narcophin retards peristalsis.). Kats ch, Ztschr. f. exp. Path. u. Ther., 19(12-)13, 12, 280 (Rabbits, abdominal window method, morphin pantopon, apocodein retards intestinal movements; a transitory arrest on j.v, application.). Z eh be, Ther. Monatsh., 1913, 27. year, 406 (Men, X-ray examination, morphine retards intestinal passage.). S cha piro, Pflügers Arch., 1913, 151, 65 (Dogs, X-ray, morphine accelerates intestinal passage.). P al, Wien. m.W., 1913, 1049 (Morphine, opium, pantopon decrease tonus of intestinal wall.). Mahlo, Dtsch. Arch. f. klin. Med., 1913, 110, 562 (Healthy students, X-ray, opium cures ricinus oil diarrhoea by acting on large intestines, then on small intestines. Not much stress on stomach.). Hesse and Neukirch, Pfü̈gers Arch., 1913, 151, 309 (Magnus' laboratory, cats, Xray, milk-diarrhoea, colocynth-diarrhoea, morphine free pantopon \& codeine delay passage in small intestines.). P o p p e r, Ibid., 1913, 153. 574 (Rabbits intestine in Ringer: morphine 1:6400 000 increases tone of circular \& longitudinal muscles.). Fir z, Arch. f. exp. Path. a. Phar'm., 1913, 74, 318 (Intestine of cats or rabbits in Tyrode: morphine stimulates circular \& longitudinal muscles.). Meissner, Biochem. Ztschr., 1916, 73, 236 (Longitudinal muscles of rabbit intestines: morphine increases temporarily amplitude and tone; small doses stimulate \& large ones inhibit; on applying into intestinal cavity moderate stimulation.). T a k a has hi, Pflügers Arch., 1914, 159, 327 (Magnus' laboratory; eats, $X$-ray, morphine \& codein delay passage in small intestines in corocynth diarrhoea; morphine + codein delays passage in small intestines and large intestines in normal cats.). Panco ast and Hopkins, J. Am. m. Ass., 1915, 65, (2220 Patients, X-ray, morphine, increases peristalsis in pylorus, delays motility of small intestines, by lack of propulsion; little consequence on large intestines.). P. Trendelen burg, Arch. f. exp. Path. u. Pharm., 1917, 81, $106 \mathrm{ff}$ : (Isolated intestines of dogs; 1:10-1:1 Million stimulates, $1: 100000$ diminishes, but never abolishes; those of rabbits: $1: 1$ Million-1:10 000 stimulates, $1: 7500$ slightly inhibits; those of cats:1:300 0001:100000 reduces peristalsis, seldom transitor's excitation. 10-12 mg. given i.v. into rabbits (?) pendular movements wholly cease.). Uhlmann and Abelin, Ztschr. f. exp. Path. u. Ther., 1920, 21, 75 (Opium preparations. Isolated intestines, of rabbits. Mag nu's method: opium preparations paralyse; in some cases stimulation occurred on relatively large doses. U h l mann's method, morphine stimulates circular \& longitudinal muscles; small doses paralyse them. Trendelenburg's method: morphine inhibits intestinal movements, but never completely. Gayda-Trendelenburg's method: increases peristalsis; but large doses paralyses. Uhlmann-Abeli n's method (Intestines in situ): Small doses paralyse peristalsis, moderate doses stimulates, large ones very strongly stimulates, followed by large relaxation.). Plant and Miller, J. of Pharm. \& Exp. Ther., 1923, 21, 202, (Dogs, rubber-ballon into Thiry-Vella's fistula: morphine, therapeutic doses in man, increases rhythmical contractions and tone. Intestine of dogs in Tyrode; relaxation.). K w a $\mathrm{n}$, Kyoto Igaku Zasshi, 1923, 20, 351 (German abstract p. 30)(Isolated intestine segment of rabbit, morphine, small amonnt stimu- 
tant report of $\mathbf{S} \mathrm{u} \hat{o}^{3)}$ affording evidences of various actions of morphine upon intestinal movements according to preparations, owing to regretable oversight; and this is offered now only as a preliminary report on a subject we hope to follow more conclusively.

lates, large amount paralyses.). Gordonoff, Kato, Kokan and Mayeda, Arch. $\mathrm{f}$. exp. Path. u. Pharm., 1925, 106, 287 (Dogs, X-ray, morphine delays small intestinal passage. Rabbits, window method, increases peristalsis \& contraction.). Bauer, Ztschr. f. ges, exp. Med., 1925, 44, 540 (Intestinal segment of rabbits, morphine excites in small doses, paralyses in large doses.). Miller and Pla $\mathbf{n}$, Proc. of Soc. for Exp. Biol. \& Med., 19(25-)26, 23, 836 (Dogs, Thiry-Vella's fistula, morphine, subc, increases tone, amplitude \& frequency of muscular activity.). Plant and Miller, J. of Pharm. \& Exp. Ther., 1926, 27, 361 (Dogs, Thirg-Vella's fistula, morphine, subc. \& i.v., increases tonus, frequency \& mplitude of peristalsis. Denervation exaggerates the action, particularly that on tonus. Experience on a patient, suffering from ileostomy, increases tonus, diminishes amplitude; cases of hernia, increases the frequency of contractions.). H a y a ma, Folia pharm. Jap., 1928, 7, 128 (Jap., German abstract-Breviaria 10. Rabbits under urethane, intestinal movements in situ. Morphine, $0.0025 \mathrm{~g}$ per kilo slightly inhibits, $0.005-0.01$ largely inhibits \& $0.02 \mathrm{~g}$ augments, then inhibits.). G $\mathbf{r} \mathbf{u}$ ber and $\mathrm{R}$ obins on, J. of Pharm. \& Exp. Ther., 1929, 37, 101 (A rather complete review rê action of morphine upon passage through digestive tract there. Dogs, Thiry-Vella's fistula, morphine i.v., $0.05 \mathrm{mgrm}$. \& $2 \mathrm{mgrms}$. per kilo, first injection increases, subsequent injections slightly decrease tonus or increases contraction force.). D reyer, J. of Pharm. \& Exp. Ther., 1929, 36, 377 (Cats, intestine movements in situ, morphine increases tonus and amplitude promptly. Denervation of that intestine segment, double vagotomy \& splanchnicotomy or suprarenalectomy has no relation to this action.). Gruber, Greene, Drager and $\mathrm{Cr}$ a w ford, J. of Pharm. \& Exp. Ther., 1930, 38, 389 (Dogs, ThiryVella's fistula, the action of morphine \& atropine upon tonus and rhythmic contraction counteracts with each other.). Gruber and Pipkin, J. of Pharm. \& Exp. Ther., $1930,38,401$ (Segment from dog duodenum \& ileum, ete., morphine increases tonus \& contraction force.). Childrey, Alvarez and M a n n, Arch. of Int. Med., 1930, 46, 361 (Dogs, distal end of ileum was joined to stump of rectum, colon being exeised, morphine slows progress of material through intestine.). Sugihara, Kondo and $M$ as uda, Keijo J. of Med., 1931, 2, 47 (Intestinal movements in situ of rabbits, fastened prone (S ugih a r'a's method), morphine i.v., 10 mgrms. per kilo, decreases amplitude \& tonus. 20 mgrms. smaller inhibition.). S u ô, Folia Pharm. Jap., 1932, 14, 113 (German abstract p. 7) (Rabbits intestinal movements in situ. Morphine, according to preparations intestinal action varies. No inhititory action in preparations from the Monopoly Bureau of Corea, a manufactory in Japan, in contrast to that from Merck, and those purified by the author himself from the preparate from Corea.). Su ô, Ibid, 260 (German referat $p$. 17), (Atropine or double vagotomy abolishes the intestinal action of morphine.). G $x u$ ber, Bryan and Richardson, J. of Pharm. \& Exp. Ther., 1932, 45, 299 (Dogs, ThiryVella's fistula, morphine abolishes at once the decreased tone and powerful peristaltic contractions caused by aloe.). Haraguchi, Nagasaki Igakukai Zasshi, 1933, 11, 71 (German abstract p. 83)(Intestinal segment of rabbits, minimum dose $0.0005 \%$, decreases tonus \& amplitude, $1 \%$ paralysis. Intestinal movements in situ, $0.01 \mathrm{~g}$ pro kilo standstill or diminution, sometimes excites. No aetion of morphine after atropine. Double splanchnicotomy not effect the action at all. Double splanchnicotomy with destruction of the cervical cord, no inhibition by morphine, but rather angmented. Removal of cerebral cortex or double vagotomy not effect the action. Double vagotomy with double splanchnicotomy somewhat diminishes the inhibitory action.).-"intestinal movements" in the references referred to those of small intestines only. 
In the present investigations rabbits of both sexes were used; no food (tofukara) was given for 24 hours before the experiment. The rabbit was prepared for recording the intestinal movements in vivo according to the method of Trendelenburg; an animal was fastened supine on a table without giving any narcosis, and a median incision of about 4-5 cms. length was made through the linea alba between the xiphoid process and the umbilicus. The intestine down from the outlet of the pancreatic duct was then pulled out and both ends of a given portion of about three centimeters were stitched to the small holes, bored diametrically on the lower inlet of the metallic cylinder. About in the middle of the intestine portion a thread was attached, the another end of the thread being connected to the Gohara's lever. through the small hole at the cornical top of the metallic cylinder. The lower portion of the cylinder with the intestinal portion attached there was then put into the abdominal cavity and fixed to the incision opening by means of double guards. Bodily warmed Tyrode's solution was poured into the abdominal cavity, through the cylinder, and the portion of cylinder above the incision opening was warmed by means of a double layered metal box, which is just adapted to cover the cylinder and has inlet and outlet tubes for letting hot water of about $38^{\circ}$ to run through.

About half an hour has to elapse for recording some regular intestinal movements.

Morphine hydrochloride (Torii) was dosaged as $0.001,0.0025$, $0.005,0.01,0.02$ or 0.04 grms. per kilo of body weight and injected into a jugular vein on diluting with the saline solution. Each injection was made with an interval of thirty minutes or more.

In normal rabbits, 15 in number, 1 mgrm. morphine per kilo showed no effect at all. $2.5 \mathrm{mgrms}$. decreased promptly the intestinal tone and reduced the anplitude as well as the rhythm of peristalsis. Such effects lasted about half a minute; three to five minutes later the curves appeared just as before the injection. These effects appeared more distinctly and long continued when 5 mgrms. were the dose. When $20 \mathrm{mgrms}$. were dosaged, the effect was capricious, that is, excitatory phenomena appeared in some cases, but in the other the inhibitory were the outcome. On a larger dose, viz. $40 \mathrm{mgrms}$. per kilo, the intestinal movements were augmented, the tone became higher and the peristalsis greater, and such effects continued for 3-20 minutes.

4) P. Trendelenburg, Ztschr. f. Biol., 1913, 61, 67.

5) Gohara, Acta Schol. med. Kioto, 1918, 2, 339. 
The doses causing various figures of reaction harmonize well with Hayama, Haraguchi ${ }^{3}$ etc., but it must be noted that an inhibitory effect was very insignificant in the present cases; a fact well accounted for by the evidences indicated by $\mathrm{Su} \hat{\mathrm{o}}$.

No material alteration occurred in the heart rate; tachypnoea and body temperature fall occurred.

While a retarding action of morphine upon the small intestinal movements is rather commonly recognized in cases of dogs $(\mathrm{Pal}, \mathrm{Dix}$ on, $\mathrm{B}$ enczúr, Popper, Schapiro, Plant and Miller and Gordonoff et al. against Legros \& Onimus and Salvioli, etc.), cats (Dix on and Popper against Magnus) and especially of men (Arnsperger, Stierlin \& Schapiro, Zehbe, Mahlo and Pancoast and Hopkins), different figures were obtainable in cases of rabbits, either acceleration or inhibition. ${ }^{3)}$ According to some writers, such as Nothnagel, Bokai, Hayama, Su ô, Haraguchi, smaller dose of morphine act to reduce the intestinal movements, and larger doses to augment ${ }^{3}$; the present results coincides with the latter. If the concentration of morphine in blood be reckoned, doses of $2.5 \mathrm{mgrms}$. to $10 \mathrm{mgrms}$. per kilo correspond to 5$20: 100000$ and 40 mgrms. per kilo to $80: 100000$. (The total blood quantity of rabbits is taken as one twentieth of the body weight.). These figures don't seem to harmonize well with those given by Trendelenburg for isolated intestine segments of rabbits. ${ }^{3)}$

Using a Thirg-Vella's fistula Plant and Miller, ${ }^{3}$ ) and Gruber with his co-workers ${ }^{3)}$ noted in dogs action of morphine of increasing the tonus of gut; Plant and Miller further noted an increase of rhythmic contractions and am. plitude, and Gruber noted an increase of peristaltic activity on a small amount of the drug and a reduction on a moderate amount.

Further Plant and Miller ${ }^{3}$ who utilized occasions to make a direct observation of intestinal movements on patients, witnessed an increasing tonus, a diminishing amplitude and an increasing frequency of contractions on morphine.

Of cats, Drey er ${ }^{3)}$ noted morphine stimulates intestinal movements. The extensive work of Takahashi, ${ }^{3)}$ carried out in the laboratory of Magnus, is particularly worth while noting. Morphine acts to retard intestinal movements in cats suffering from colocynth diarrhoea, and the same action was observed even in normal cats when morphine was combined with codeine. A report of $\mathrm{Hesse}$ and $\mathrm{Neukirch},{ }^{3}$ ) of retarding action on intestinal movements in cats suffering from milk or colocynth diarrhoea of morphine-free pantopon and codeine preceded that of $\mathrm{T}$ akahashi, above quoted. Is it not fair to take these reports as possibly showing turning of the view of Magnus rê the action of morphine on intestinal movements? It is common still nowadays to quote of Magnus the old view only.

The same morphine experiment was carried out in some doubly splanchnicotomized, suprarenalectomized or medulli-suprarenalectomized rabbits. The operation was performed per laparotomiam about 
two weeks intervening between both that on both sides, and three months or more were allowed to elapse from the last operation and the morphine experiment.

In these experiments the augmenting action of larger doses of morphine upon intestinal movements was also registered, but the inhibiting action of smaller doses became manifest only infrequently and in a minor degree, as shown in Fig. 2 against Fig. 1 obtained from normal rabbits. In both cases $0.01 \mathrm{grm}$. was the dosage, and Fig. 2 originates from a rabbit with demedullated glands. Time in 5 seconds.
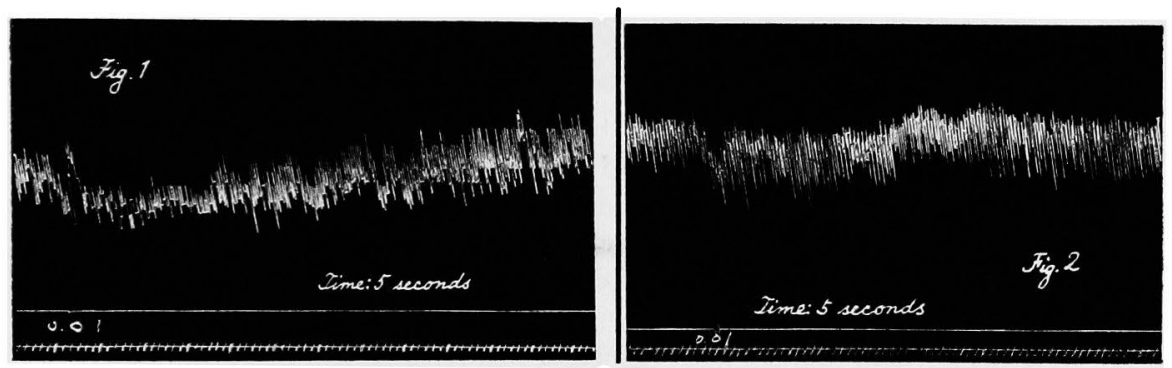

In relation to the action of, morphine upon the intestines, the splanchnic nerves have been tested from time to time. Nasse mentioned that morphine does not paralyse the splanchnic nerves, and Nothnagel tried to explain the inhibiting effect of smaller doses of morphine by an excitation of splanchnic nerves and the augmenting one of greater doses by a paralysis of the neives. Pal and Berggrün related that interference of the splanchnics abolishes the effect of morphine to reduce the excitability of intestines.

According to Dreyer, ${ }^{3}$ a stimulating effect of morphine upon the intestines cannot be modified by interfering with vagi, splanchnici and suprarenal capsules. Su ô observed double vagotomy abolishes the intestinal action of morphine; atropine acts similarly, which corresponds to the findings of Gruber, Green, Drayer and Crawford. Haraguchi found however non-effect of double splanchnicotomy, vagotomy, removal of cerebral cortex upon intestinal action of morphine while a combination of double vagotomy and splanchnicotomy makes weak the action and that of double splanchnicotomy with removal of the cervical cord nullifies the inhibitory action.

Dix on saw a somewhat smaller augmenting effect of apocodein in cats after splanchnicotomy and $\mathrm{Magnus}$ obtained quite the same effect of arrest- 
ing diarrhoea in cats fed with an excessive amount of milk before and after double splanchnicotomy.

Jac obj noted an acceleration of the action of the vagus nerve on removing the suprarenals, which is not altered by administering morphine. Vámoss y's findings did not coincide with $\mathrm{Jacobj}$, that is, morphine abolishes it.

Under our experimental conditions morphine hydrochloride, intravenously applied, exercises an inhibitory influence upon the small intestine movements and tone when given in small doses such as 2.510 mgrms. per kilo of body weight and an augmentatory influence on larger doses as $40 \mathrm{mgrms}$. per kilo; interference of the splanchnic nerves, the suprarenals or the suprarenal medulla reduces or abolishes the effect of the smaller doses of morphine while the larger doses elicit the augmenting influence as in the normal animals.

If the explanation of Hayama be applicable, though Hayama and the present writer made use of the intestine segment, non-denervated, it might be thought that the epinephrine secreted on morphine intoxication covers all the rôle played by excitation of the splanchnic nerves, that is the immediate effect of the nerves upon the intestines and the intermediate due to discharge of epinephrine.

However, since we did not concern of the sorts of morphine preparation, as we did not know of the interesting report of $\mathrm{Su}$ o while these experiments were carried out, and the preparation used here is different from that used by Ha y a ma and Harag u chi who made use of that of Merck, it is difficult to compare and discuss the present data with theirs, which must be delayed till the present plan will be repeated with another preparation better qualified. 